\title{
A persuasão pelo caráter do orador em Antonio Vieira
}

The persuasion by the character of the rhetor in Antônio Vieira

Talita Cristina Rocha ${ }^{1}$

Resumo: Este estudo objetiva analisar as provas arregimentadas por Antônio Vieira para constituir seu ethos em diferentes discursos, em uma carta enviada ao rei de Portugal no dia 20 de maio de 1653 e no sermão da Epifania, de 1662. Para isso, foi necessário discutir questões pertinentes à retórica, arte que fundamentava a produção letrada do Seiscentos. As conclusões que serão apresentadas apontam para uma dúbia configuração do ethos do jesuíta, dada a adequação do discurso a cada situação.

Palavras-chave: Antônio Vieira. Ethos. Carta. Sermão. Agudeza.

Abstract: This study aims to analyze the evidences gathered by Antônio Vieira to constitute his ethos in different speeches, in a letter sent to the king of Portugal on May 20, 1653, and in the sermon of Epiphany, 1662. To that purpose, it was necessary to discuss pertinent questions to the rhetoric, art that founded the literary production of the Seventeenth century. The conclusions that will be presented point to a dubious configuration of the Jesuit ethos, given the appropriateness of the discourse to each situation.

Keywords: Antônio Vieira. Ethos. Letter. Sermon. Wit.

1 Mestranda no Programa de Pós-Graduação em Letras da Universidade Federal de São Paulo (Unifesp). 
Talita Cristina

Rocha

Ao refletir sobre os discursos que circulavam no Brasil do Seiscentos, é possível identificar o importante papel das cartas e dos sermões nas esferas política e social, além do compromisso teológico desses textos. Nesse período, as companhias religiosas tiveram muita relevância para consolidar os projetos de colonização do Novo Mundo, pois cuidaram da expansão da fé cristã entre a chamada "gentilidade", isto é, os índios que habitavam tais terras. Para que a atuação sobre as almas fosse cumprida, a palavra foi santificada e tomada como principal instrumento de persuasão. Portanto, adequar-se ao substrato da retórica era imprescindível para que houvesse a persuasão e, consequentemente, a redenção dos pecados.

Nesse contexto político-religioso, o membro da Companhia de Jesus, mestre de retórica, teólogo, intérprete, embaixador e outras tantas particularidades, padre Antônio Vieira, se consagrou por sua notável produção de sermões. Esses discursos eram proferidos nos púlpitos, visando a alcançar o convencimento dos interlocutores, por meio da explanação que o orador sacro fazia de uma escritura bíblica. Para que os fiéis compreendessem mais facilmente a mensagem pregada nos púlpitos, os padres apresentavam uma imagem muito vívida por meio da evidentia, "descrição detalhada de um objeto por meio da enumeração ornada de suas particularidades reais ou fantásticas. No âmbito das representações do século XVII, a evidentia é preferencialmente aguda" (HANSEN, 2000c, p. 320), constituindo-se como prova para atrair a imaginação do ouvinte e convencê-lo a mudar seus hábitos.

Além de sua conhecida produção sermonística, Vieira trocou inúmeras correspondências com destinatários também preocupados, ou interessados, com o projeto de catequese dos gentios, por ser a comunicação epistolar o principal veículo para troca de informações entre sacerdotes da Companhia de Jesus. Por conta de seu papel na missão, as cartas escritas pelo jesuíta tratam de questões específicas da evangelização do Novo Mundo.

Independentemente do gênero, sermão ou carta, quando a produção textual do Seiscentos é examinada, as preceptivas retóricas devem ser levadas em consideração imprescindivelmente. Postulações de filósofos e oradores como Aristóteles e Cícero regiam a composição letrada, apontando normas e modelos de escrita que deveriam ser seguidos. Esses modelos eram transmitidos por meio do ensino e deviam ser acomodados para que um discurso fosse tido como adequado. 
Segundo Aristóteles, na Poética, a mímesis é entendida como própria do homem: "imitar é natural nos homens desde a infância e nisto diferem dos outros animais, pois o homem é quem tem mais capacidade de imitar e é pela imitação que adquire os seus primeiros conhecimentos" (ARISTÓTELES, 2008, p. 42). Em seu Tratado da Imitação, Dionísio de Halicarnasso a entende como "uma actividade que, segundo determinados princípios teóricos, refunde um modelo" (1986, p. 49). Todavia, isso não significa que se deva dizer o mesmo que um modelo diz, mas à maneira desse modelo. Além disso, não bastava imitar somente um modelo, mas todos os que elevariam o que se pretendia dizer, "porque os melhores discursos, os que são dignos de imitação, são aqueles que não têm as características de um só, mas de vários" (ibid. p. 69). Posteriormente, para os latinos, o conceito de imitatio passa a corresponder à

A persuasão pelo caráter do orador em Antônio Vieira imitação dos grandes modelos, tomando-os como referência (HORÁCIO, 2005 , p. 59), e aparece vinculado aos domínios da filosofia, da linguagem, da política, entre outras áreas do saber humano. A partir dessa noção, entende-se a percepção dos antigos quanto à produção de um bom texto. Anteriormente à prevalência da modernidade, as letras se inseriram em uma produção mimética, ou seja, partindo de um conjunto de doutrinas e regras praticado coletivamente e durante séculos reescrito, fundamentado na arte retórica. Essas normas resistiram por mais de dois milênios, fazendo com que os textos tivessem uma composição prevista em modelos discursivos emulados pelos autores.

Como parte dessa tradição que imitava modelos retóricos, padre Antônio Vieira tem notoriedade por sua vasta produção textual. De sermões e profecias a cartas documentais, o religioso sempre evidencia nos discursos seu envolvimento político. Além de ser missionário da Companhia de Jesus, ordem católica responsável pelo evangelismo dos gentios do Novo Mundo, Vieira, até certo ponto de sua trajetória, tinha grande confiança da Coroa portuguesa, sendo valido do rei, o que o permitia opinar sobre algumas questões referentes aos negócios da colonização.

Portanto, em seus discursos, orais ou escritos, Vieira se preocupava em compor um ethos que lhe assegurasse credibilidade. Esse conceito também diz respeito às postulações aristotélicas, enquadrando-se entre as provas que alcançam a persuasão dos interlocutores, que são levados a perceber o mundo e agir em conveniência com os argumentos defendidos no discurso. Portanto, os oradores são persuasivos por conta da pru- 
Talita Cristina

Rocha

156

dência, da virtude e da benevolência, pois são as paixões que introduzem mudanças no juízo e nas ações humanas. Para que isso ocorra, conforme Aristóteles (2005, p. 96-97), além do ethos ( $\eta 0$ os), é necessário que duas

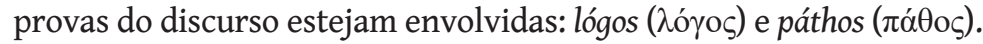

Pelas sistematizações da retórica, o ethos corresponde à imagem que o interlocutor terá daquele que produz o texto, manifestando-se no conteúdo e no modo com que algo é expressado. Por isso, o locutor compõe discursivamente uma imagem que seja convincente, que produza confiança nos ouvintes, visando a influenciá-los afetivamente. Todavia, além das provas éticas, para que a persuasão seja efetivada, é preciso que a veracidade da matéria seja comprovada pela lógica, bem como que o discurso provoque algo em quem o escuta, tocando as paixões do interlocutor. À vista disso, compreende-se o quão importante são essas provas discursivas para o êxito de um texto.

Por outro lado, no De Oratore (2009, p. 233), Cícero trata das características que o orador deve ter para alcançar o convencimento do público, "tal como aquela outra parte do discurso, que deve contemplar a espécie do homem bom pela recomendação de sua honestidade, é branda [...] e simples, esta, que, é empreendida pelo orador para alterar os ânimos e influenciá-los por todos os meios, deve ser rigorosa e veemente". Dessa forma, vê-se que, do ponto de vista ciceroniano, o caráter do orador não se constrói somente no discurso, como para Aristóteles, mas envolve uma questão ética, a reputação da vida do orador.

Nos discursos de Vieira, dessa forma, há uma junção entre as postulações aristotélicas e ciceronianas. Para garantir que ele é veículo da voz da verdade, o padre arregimenta provas discursivamente construídas, compondo seu ethos, assumido em um tom grave e prudente, e também se vale de sua reputação como missionário, composta em larga escala pelos títulos que tinha e posições que ocupava, para que seu discurso fosse considerado verdadeiro. Assim, Antônio Vieira mostra que representava a vontade da Palavra do próprio Deus e que, por isso, os interlocutores deveriam ouvi-lo. Isso ocorre nas cartas, nas quais o jesuíta, comumente, discorre sobre assuntos da missão evangelística, e nos sermões, nos quais as pregações visam ao convencimento dos fiéis.

Outro ponto de convergência entre as epístolas e as pregações de Vieira é o estilo pedestre, visto que esses textos evidenciam uma simplicidade elegante quanto à linguagem. Essa estratégia textual é utilizada para que o locutor seja claro a ponto de levar o ouvinte à compreen- 
são e, em seguida, persuadi-lo. Esses ensinamentos são providos pelas artes retóricas. Conforme Grigera (1994, p. 18), nos tratados latinos, o estilo de um discurso deveria se enquadrar em pedestre, médio ou grave, relacionados, respectivamente, aos gêneros epidítico, deliberativo e judiciário. Esses gêneros da elocução circularam entre os antigos e embasaram as tradições retóricas. Os discursos do padre Antônio Vieira evidenciam essa adequação ao que foi retoricamente sistematizado, enquadrando-se primordialmente no gênero epidítico ou demonstrativo, gênero originalmente empregado para o elogio ou o vitupério.

Isso aponta para a questão de os textos não serem autônomos da educação e da disciplina recebida pela Companhia de Jesus. Para que houvesse essa unicidade na educação jesuítica, a Ratio Studiorum, um conjunto de preceitos retórico-doutrinários que pautava o magistério

A persuasão pelo caráter do orador em Antônio Vieira dos eclesiásticos na missão, era ensinada aos sacerdotes ainda no seminário. Por meio dessas constituições e regras da Companhia, os discursos dos jesuítas mantinham sempre um vínculo de obediência à Ordem (FRANCA, 1952). Em sua obra La Retorica Eclesiastica, frei Luís de Granada, um padre dominicano mestre em retórica e eloquência, evidencia sua formação nos antigos gregos e latinos. Esse manual de Granada fazia parte da formação escolar fundamental que os jesuítas recebiam por meio da Ratio studiorum. Nele, a relação entre retórica e persuasão é evidente: "se debe aprender el arte de la retórica, para que podamos persuadir al pueblo lo que queremos" (GRANADA, 1775, p. 04). Por esse motivo e, também, para garantir a obediência à Ordem jesuítica, preceptivas retóricas eram estudadas e praticadas pelos religiosos. Quando se adequavam a essas postulações de forma bem sucedida, os sacerdotes asseguravam uma auctoritas (HANSEN, 2000a, p. 33; 1992, p. 17 e 28), uma autoridade, pois seguiam os grandes mestres.

Quanto às cartas escritas por Vieira, vê-se a acomodação às preceptivas retóricas. Isso se confirma pelas provas éticas facilmente encontradas, pelo decoro, pela adequação das partes do texto e por tantas outras características. Dessa forma, é válido considerar as particularidades desse gênero tão comum às letras do século XVII.

Partindo dessa perspectiva sistêmica dos gêneros praticados no Seiscentos, a carta é constituída por um contrato enunciativo em que o remetente escreve para um destinatário, servindo como um meio de comunicação entre eles. Marcadas pela pessoalidade, as cartas tocam em assuntos particulares e em matérias que tratam de questões civis, 
Talita Cristina

Rocha

servindo de base para uma suposta conversa entre pessoas ausentes, como postulado por Cícero: "há muitos tipos de carta, mas o único mais certo é aquele por cuja causa a própria carta foi inventada: para que informássemos os ausentes se ocorresse algo que eles soubessem que interessaria a nós ou a eles mesmos" (ad Fam., II, 4, 1). Desse modo, vê-se que os textos são relacionados a uma finalidade retórica da utilidade, a uma finalidade pragmática, visto que visam a informar.

Conforme Tin (2005, p. 31), até a dita Idade Média, as artes epistolares das Antiguidades, depreendidas de missivas como as de Cícero, foram muito praticadas. Contudo, dada a necessidade de um estilo formal mais rígido, tratados acerca da técnica de fazer cartas foram elaborados.

Em seu pequeno manual, intitulado Epistolica Institutio, Justo Lípsio (1547 - 1606), um humanista flamengo, define o texto epistolar como "uma notícia escrita de um espírito a outro ausente" (Idem, 2005, p. 132), com o objetivo de tratar de um assunto e afirmar um sentimento. Como apresentado no mesmo texto, o motivo pelo qual se escreve uma carta é a matéria, o assunto de que se irá tratar. Nas Regras para escrever cartas, cujo tratadista é anônimo, a carta é entendida como "um discurso composto de partes ao mesmo tempo distintas e coerentes, significando plenamente os sentimentos de seu remetente" (Idem, 2005, p. 83).

Quanto às partes que a carta deve ter, nos manuais parece haver um consenso, sendo elas: salutatio, uma saudação breve; exordium e captatio benevolentiae, parte introdutória da correspondência em que já se usará uma estratégia para atrair a benevolência ou a boa disposição do destinatário; narratio, a parte mais substancial da carta, em que os eventos sucessivos são contados; argumentatio, tentativa de moção dos afetos do destinatário, por meio da persuasão; petitio, reiteração de solicitações feitas no início do texto; conclusio, a conclusão da carta; subscriptio, assinatura e data (HANSEN, 2003, p. 47-55). Essas preceptivas de composição circulavam entre os homens letrados, para que fins práticos fossem cumpridos. Arranjadas, as partes do texto expressam em palavras a mensagem que o remetente pretende transmitir.

$\mathrm{Na}$ carta, é odiosa a tagarelice, já que o discurso epistolar deve contar com as virtudes retóricas da clareza e da brevidade (LÍPSIO, 2005, p. 141), o que o aproxima dos preceitos da conversa cotidiana e pedestre. Entretanto, o gênero epistolar acaba se distanciando do diálogo no que se refere à elaboração exigida, porque não permite a improvisação de um discurso construído na interlocução no momento em que se fala. 
Além do estudo da retórica, os membros da Companhia de Jesus também deviam se adequar às postulações da Ordem comunicando-se, frequentemente, por meio de cartas. Pode-se perceber a importância e função atribuídas à escrita epistolar neste excerto das Constituições Inacianas:

$\$ 673$ - Concorrerá também de maneira muito especial para esta união [da cabeça com os membros em geral], a frequente correspondência epistolar entre súditos e superiores, com o intercâmbio de informações entre uns e outros, e o conhecimento das notícias e comunicações vindas das diversas partes. Este encargo pertence aos superiores, em particular ao Geral e aos Provinciais. Eles providenciarão para que em cada lugar se possa saber o que se faz nas outras partes, para conA persuasão pelo caráter do orador em Antônio Vieira solação e edificação mútuas em Nosso Senhor (Constituições da Companhia de Jesus, 1997, p. 211).

Tomando a carta como um gênero do discurso, entende-se que seu contrato enunciativo faz menção à relação de pessoalidade, um "eu" que escreve para um "tu". Como firma uma vinculação performativa entre remetente e destinatário, é necessário que os textos epistolares estabeleçam adequadamente o decoro. Isso ocorre por meio da adequação semântica e pragmática da enunciação, como salienta Grigera (1994, p. 124). A aplicação do decoro para a constituição do ethos de Vieira era essencial para o direcionamento adequado ao destinatário. Como postulado por Hansen:

Nas cartas, Vieira aplica preceitos da ars dictaminis [...], por isso o modo como o remetente nelas se dirige ao destinatário não é jocoso, se o destinatário é de condição superior; não é descortês, se é de igual condição; e não é orgulhoso, se de condição inferior. Logo, também o modo como o remetente saúda o destinatário na abertura da carta e o modo como se despede dele no final evidenciam o decoro específico da sua posição. (2000b, p. 270)

Portanto, para garantir uma enunciação decorosa, o jesuíta elaborava discursivamente provas éticas que demonstrassem um caráter grave e prudente. Essa enunciação era o esperado da persona de um padre. 
Assim, em correspondência enviada ao rei de Portugal no dia 20 de maio de 1653, o padre Antônio Vieira já inicia o discurso marcando a distância adequada à figura do rei, tratando-o por "Senhor". o jesuíta, em todas as partes da carta, garante a composição de um ethos que aponte para a humildade esperada de um padre, recorrendo ao decoro que reforce sua sujeição ao rei. Após uma breve saudação, Vieira inicia com a captação da benevolência, recordando D. João IV da escolha de mandar o jesuíta português como missionário nas novas terras da Coroa:

Talita Cristina

Rocha

160

"Senhor. - Como V.M. foi servido encomendar-me tão particularmente a conversão da gentilidade deste Estado, e a conservação e aumento de nossa santa fé nele, faltaria eu muito a esta obrigação, e à da consciência, se não desse conta a V.M. dos grandes desamparos espirituais que em todas estas partes se padecem, apontando com toda a brevidade que me for possível os danos as causas deles, e os remédios com que se lhe pode e deve acudir (VIEIRA, 2003, p. 432).

Além de destacar seu lugar de súdito, Vieira tenta captar a benevolência do destinatário mencionando que será breve na exposição que se seguirá na narratio. Tal comentário salienta a preocupação do padre em adequar a carta à composição prescrita para o gênero, em que a prolixidade do falar é dispensável. Essa preocupação com a brevidade é retratada na Retórica a Herênio (2005, p. 67), sendo a brevitas uma qualidade tão importante quanto a clareza e a verossimilhança para a narração.

Dessa forma, enquanto narra o lugar do índio na sociedade colonial, de maneira breve, clara e verossímil, Vieira diz nessa carta que os gentios, infinitos em número e em diversidade de línguas, vivem espalhados pelos sertões. Dos que vivem entre os portugueses, livres ou cativos, a maioria é cristã. Em seguida, o remetente trata da falta de doutrina dos portugueses que habitam a América Portuguesa, discorrendo acerca das possíveis causas dessa infidelidade: a falta de igrejas curadas e o despreparo dos sacerdotes. Nesse caso, como muitos índios vivem nas casas dos lusitanos, os nativos morrem pagãos, sem ao menos confessarem a fé ou passar pelo batismo, o que consiste em um grande desamparo espiritual. Para o missionário, o grande remédio contra o problema da perdição seria o envio de religiosos que dessem continuidade ao projeto de doutrinação dos índios, dada a pequena quantidade de eclesiásticos para o tamanho da seara. 
Ainda nessa correspondência, Vieira denuncia a cobiça dos colonos em escravizar os índios. Ele fala sobre as invasões às aldeias, comentando que o remédio dado pelo rei D. João IV e por seus antecessores, de proibir os resgates nos sertões, não foi suficiente para garantir a liberdade dos nativos. O mesmo ponto de vista é adotado quando o jesuíta comenta a situação dos índios que não possuíam um senhor, mas que eram obrigados a servir os governadores e capitães-mores nas grandes lavouras. Para o inaciano, as únicas entradas nos territórios indígenas deveriam ser com finalidade de evangelização, para que os gentios fossem convertidos. Todas essas petições são feitas ao rei respeitando-se a posição de súdito de Vieira.

Por fim, na conclusio, o jesuíta retoma a questão do padecimento da alma do índio, chamando a atenção do rei para as causas apontadas. A persuasão pelo caráter do orador em Antônio Vieira Vieira conduz o discurso reforçando a gravidade de seu ethos, ou seja, a imagem esperada de um padre que doou seus ânimos para a evangelização de gentios, a fim de que $\mathrm{D}$. João desse credibilidade à mensagem e se comovesse com a situação apresentada:

\footnotetext{
Isto é, senhor, o que me pareceu representar a V. M., por satisfazer à minha obrigação e por descargo da minha consciência, encarregando muito, com toda a submissão que devo à de $\mathrm{V}$. M., o remédio destes gravíssimos danos que padecem tão infinitas almas, de todos os quais Deus há de pedir conta a V. M., e muito maior depois de chegarem às reais mãos de V. M. estas notícias, não de ouvidas, mas de vistas e experiência, mandadas por quem V. M. muito bem conhece que não veio buscar ao Maranhão mais que o maior serviço e a maior glória de Deus, e que abaixo d'Ele nenhuma cousa procurou nunca nem amou tanto como o serviço de V. M. (VIEIRA, 2003, p. 436).
}

Quanto a essa estratégia empregada por Vieira, de louvar seu ofício como alguém que trabalha para a glória de Deus, é uma postulação da Retórica a Herênio. Uma das maneiras apontadas no tratado para captar a benevolência do ouvinte é fazê-lo baseado na própria figura do emissor do discurso, sem que haja arrogância (2005, p. 59). Ao falar sobre si com humildade, o jesuíta está arregimentando mais provas éticas para o seu discurso, colocando-se como um servo do evangelho. Dessa forma, vemos que o ethos do remetente é adequadamente composto por meio das pro- 
vas que residem na imagem que o locutor compõe de si para alcançar o convencimento do ouvinte, conforme as postulações aristotélicas (Idem, 2005, p. 96). Espera-se, assim, que o ethos do orador seja aquele de um homem bom (CÍCERO, 2009, p. 233) e que, posteriormente em uma cosmovisão cristã, seja o do vir christianus, o bom cristão agostiniano.

Enquanto nessa carta Vieira fala sobre seus próprios feitos com a finalidade de alcançar o convencimento, no sermão da Epifania (1662) o jesuíta afirma o seguinte:

Talita Cristina

Rocha

162
Para que Portugal na nossa idade possa ouvir um Pregador Evangélico, será, hoje, o Evangelho o Pregador. Esta é a novidade que trago do Mundo Novo. O estilo era que o Pregador explicasse o Evangelho: hoje o Evangelho há de ser a explicação do Pregador. Não sou eu que hei de comentar o Texto; o Texto é o que me há de comentar a mim. Nenhuma palavra direi que não seja sua, porque nenhuma cláusula tem que não seja minha. Eu repetirei suas vozes, ele bradará os meus silêncios (VIEIRA, 2014, p. 593).

Nesse sermão, a prova ética se mostra oposta à estratégia empregada na missiva, pois Vieira retira os holofotes de sua figura para dar luz à Palavra. Tal direcionamento do padre deve-se à finalidade retórica, pois se esperava que os ouvintes fossem persuadidos por meio da pregação. Isso ocorreria somente a partir da junção das três instâncias do sermão, a religiosa, que correspondia à fonte bíblica ou à tradição cristã; a circunstancial, ligada a alguma ocorrência que incidisse sobre um fato do mundo; e a litúrgica, referente à ocasião pela qual a missa estava ocorrendo. Com essas três pontas unidas pelo pregador durante seu discurso (MUHANA, 2005, p. 28-32), seria possível gerar nos ouvintes o desengano, um descontentamento do fiel com suas atitudes que causaria uma mudança de hábitos. Essa finalidade persuasiva da oratória aparece em Cícero como a capacidade "de cativar as multidões de homens, conquistar suas mentes, impelir para onde se quiser suas vontades, desviá-las igualmente de onde se deseje" (CíCERO, 2009, p. 152).

Todavia, para que o fiel fosse cativado e a persuasão ocorresse, o engenho do orador sacro em predicar era essencial. Esse engenho no sermão da Epifania mostra-se por meio do cuidado de Vieira em não bendizer suas ações, visto que na ocasião dessa pregação os jesuítas haviam sido expulsos das missões do Maranhão, devido à fúria do povo, pois os evangelistas de- 
fendiam a liberdade dos índios. Desse modo, era necessário conscientizar os ouvintes da importância da propagação da fé cristã entre os gentios, para então conseguir o retorno à colônia com os devidos remédios assegurados.

Para captar a benevolência dos ouvintes, empregando um procedimento retórico, além de colocar-se em segundo plano, Vieira explora a matéria que está apresentando nessa pregação ao construir agudezas, como no seguinte trecho: "os magos estendendo os raios da sua Estrela por todo o Mundo Velho até às gargantas do Mediterrâneo; e eles alumiando com o novo Sol a todo o Mundo Novo até às balizas do Oceano" (VIEIRA, 2014, p. 596).

O conceito de agudeza aparece já em Aristóteles (2005, p. 265): “Agudas, pois, são as expressões do pensamento que permitem um aprendizado rápido"; e é discutido pelos latinos, como o anônimo da

A persuasão pelo caráter do orador em Antônio Vieira Retórica a Herênio, Quintiliano e Cícero. Nessa recepção das postulações aristotélicas, entende-se um discurso "ilustre" como aquele com palavras escolhidas e translações que possibilitam à imaginação remontar as imagens discursivamente apresentadas (Retórica a Herênio, 2005, p. 269). Para que isso ocorresse, um orador precisaria dispor de grande engenho, pois as complexas relações não deveriam soar como previamente preparadas. No século XVII, Emanuele Tesauro, partindo dessa mesma tradição, entende a metáfora como fundamento da agudeza, tratando-a por "Grande Mãe de todo engenhoso Conceito" (TESAURO, 1670 , apud HANSEN, 2000b, p. 321). As agudezas emanavam dos discursos de gêneros retoricamente ensinados, como nos discursos de Vieira.

No caso da agudeza do Sol que iluminou o Novo Mundo, enunciada no sermão de 1662, entendemos sua finalidade para unir a matéria mundana, o projeto de evangelização dos gentios, ao texto bíblico que faz referência ao nascimento de Cristo e à estrela que os reis magos perseguiram para encontrá-lo. Quanto a essa questão, conforme pontuou Hansen:

\footnotetext{
aplicando a interpretação às matérias mundanas do seu tempo e nelas rastreando as sombras, os vestígios e as imagens da Palavra como a prefiguração e a pós-figuração proféticas da finalidade transcendente do reino guiado por um "príncipe fatal", Vieira busca nos casos retóricos o sentido literal, o alegórico, o tropológico e o anagógico, distribuindo-os em feixes de significações adequadas à ocasião $(2008$, p. 11).
} 
Talita Cristina

Rocha

164

Assim, tanto nas cartas como nos sermões, o emprego de agudezas era adequado para a elevação do discurso. Mas a ocasião, a matéria e a finalidade do discurso é que apontam para os usos mais decorosos, inclusive quanto às provas do caráter do orador. Nesse sentido, para dar evidência ao projeto de catequese e a suas petições, no sermão da Epifania (1662) Antônio Vieira indica aos ouvintes que não tratará de si, que irá anular-se, muito embora resultem dessa técnica provas que firmam o ethos do pregador como um bom cristão que evidencia o Evangelho em vez de louvar suas glórias pessoais.

Ainda que possam ser vistas diversas constituições do ethos de Vieira na carta e no sermão analisados - na epístola são louvados os feitos do missionário, enquanto na pregação é frisada a necessidade de não engrandecer o evangelista, mas fazer com que a Palavra fale sobre o pregador -, encontramos uma unidade entre os discursos a partir da finalidade persuasiva comum. Para alcançar o objetivo de mover os ânimos do interlocutor, é necessário acomodar decorosamente o discurso, essencialmente pelo devido dimensionamento do caráter do orador, constituído discursivamente, seja na carta, seja no sermão.

\section{Considerações finais}

O decoro da carta e do sermão analisados mostra a adequação de Vieira às preceptivas retóricas, no papel de orador. Relacionando-se com a agudeza, os recursos notabilizam o quão engenhoso é o jesuíta. Como apontado, as provas que expõem o caráter do orador são construídas discursivamente, a partir de modelos retóricos. Somente com a devida acomodação das provas éticas, patéticas e lógicas, o discurso encontra sua finalidade, a persuasão.

Nesse sentido, a enunciação assegura o distanciamento entre o remetente e o destinatário da carta, por meio do ethos, que assume características adequadas à persona de um padre. Escrevendo ao rei D. João IV, Vieira precisava forjar o caráter discursivo de um religioso dedicado à missão, além de se adequar ao papel de súdito. Em correspondências à autoridade máxima portuguesa, o jesuíta não deixava de apresentar narrativas que compusessem a situação dos índios, que sofriam nas mãos dos colonos, nem de tratar da sua empreitada em prol da missão evangelística, mas isso após agradecer a dedicação da Coroa com a missão, visto que queria alcançar a benevolência de seu leitor. Da mesma forma, é também discursivamente que, na situação enunciativa do ser- 
mão, na qual um sacerdote representa a vontade da palavra de Deus, Vieira prefere anular-se para glorificar somente os feitos divinos. Todavia, vale ressaltar que essa postura é retoricamente técnica, visando a compor o caráter do orador na pregação como um servo totalmente submisso a Deus.

Portanto, é possível compreender que, pelo decoro, o padre Antônio Vieira constrói ethé diferentes, um na carta e outro no sermão, adequando-se aos destinatários e à finalidade do discurso. Como pregou o jesuíta em seu sermão do Espírito Santo (1657), no púlpito da Igreja da Companhia de Jesus, no Maranhão: "se quando o Pregador fala por fora, o Espírito Santo alumia por dentro: se quando as nossas vozes vão aos ouvidos, os raios da sua luz entram ao coração, logo se converte o mundo" (VIEIRA, 2014, p. 418). Assim, cabe ao orador, como um ministro

A persuasão pelo caráter do orador em Antônio Vieira

\section{REFERÊNCIAS}

ARISTÓTELES. Poética. Trad. Ana Maria Valente. Lisboa: Fundação Calouste Gulbenkian, 2008.

Retórica. Trad. de Manuel Alexandre Jr., Paulo Farmhouse Alberto e Abel do Nascimento Pena. Lisboa: Imprensa Naciona Casa da Moeda, 2005.

CÍCERO, Marco Túlio. Do orador. In: SCATOLIN, Adriano. A invenção no Do orador de Cícero: um estudo à luz de Ad Familiares I, 9, 23. Tese (Doutorado em Letras Clássicas) - Universidade de São Paulo, São Paulo, 2009, p. 147-308.

FRANCA, Leonel. 0 método pedagógico dos jesuítas: o "Ratio Studiorum". Rio de Janeiro: Livraria Agir Editora, 1952.

GRANADA, Fray Luis de. La Retorica Eclesiastica. Trad. Obispo de Barcelona. Barcelona: En la Imprenta de Juan Jolis y Bernardo Plá, 1775. 
GRIGERA, Luisa López. La Retórica en la España del Siglo de Oro. Salamanca: Ediciones de la Universidad de Salamanca, 1994.

HALICARNASSO, D. Tratado da Imitação. Lisboa: Instituto Nacional de Investigação Científica - Centro de Estudos das Universidades de Lisboa, 1986.

HANSEN, João Adolfo. A civilização pela palavra. In: LOPES, Eliane et al. (org.). 500 anos de educação no Brasil. Belo Horizonte: Au-

Talita Cristina

Rocha

166 têntica Editora, 2000a, p. 19-41.

. Correspondência de Antônio Vieira (1646-1694): O Decoro. Discurso, São Paulo, n. 31, p. 259-284, 2000 b.

Retórica da agudeza. Letras Clássicas, São Paulo, n. 4, p. 317-342, 2000c.

Introdução. In: VIEIRA, Antônio. Cartas do Brasil. São Paulo: Hedra, 2003, p. 18-20.

. Prefácio. In: PÉCORA, Alcir. Teatro do Sacramento. Campinas: Editora da UNICAMP, 2008, p. 9-28.

HORÁCIO. Arte Poética. Trad. de Jaime Bruna. In: A Poética Clássica. São Paulo: Cultrix, 2005, p. 53-68.

LÍPSIO, Justo. A arte de escrever cartas; Regras para escrever cartas; ROTTERDAM, Erasmo. Brevíssima e muito resumida forma. In: TIN, Emerson (Org.). A arte de escrever cartas. São Paulo: Editora da UNICAMP, 2005.

LOYOLA, Ignácio de. Constituições da Companhia de Jesus. São Paulo: Edições Loyola, 2004.

MUHANA, Adma. Quando o púlpito é teatro. Entrelivros, Editora Duetto, São Paulo, n. 05, p. 28-32, 2005.

Retórica a Herênio. Trad. Ana Paula Celestino Faria e Adriana Seabra. São Paulo: Hedra, 2005. 
VIEIRA, Antônio. Ao Rei D. João IV, 20 de maio de 1653. In:

Cartas do Brasil. Org. de João Adolfo Hansen. São Paulo: Hedra, 2003, p. 432-437.

__. "Espírito Santo"; "Epifania”. In:___. Sermões. Tomo 1. Org. Alcir Pécora. São Paulo: Hedra, 2014, p. 415-440; 593-632.

A persuasão
pelo caráter
do orador em
Antônio Vieira

167 
